

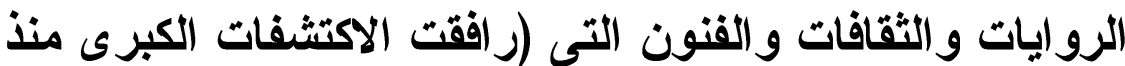

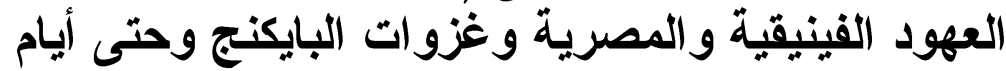

\section{كريستوفر كولون)}

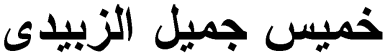

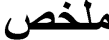

هذه الدراسة نستعرض دور الفينقيين و المصريين في الاكتثافات القديمة وما قامت به الجماعات التى تسكن شمال أوروبا منل البايكنج وحتى أيام كريستوفر

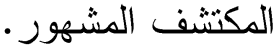

واستعرض ما رافق هذه الاكتثافات من جهود جبارة شملت اسبانيا وأمريكا

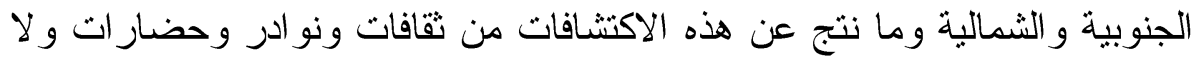

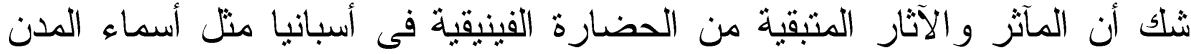

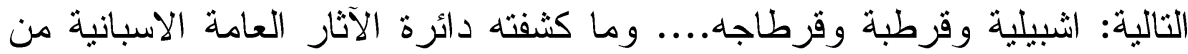

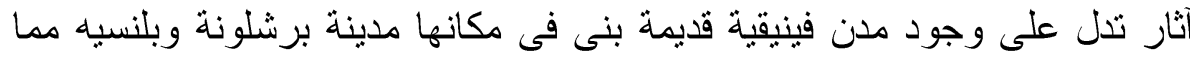

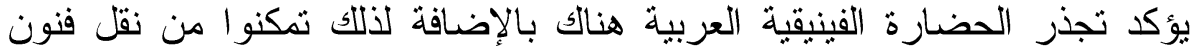

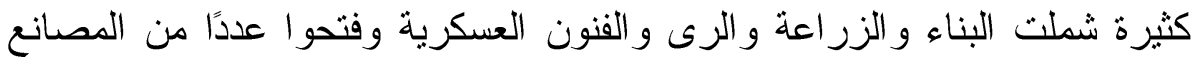

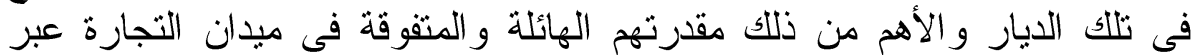

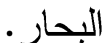

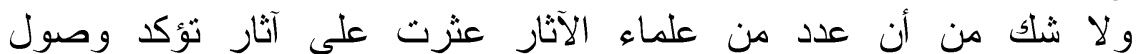

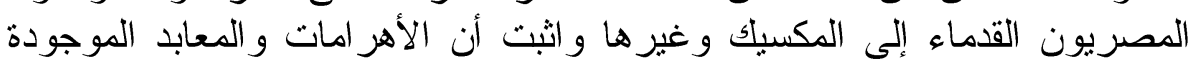
هناك متأثرة بشكل كبير بالمعرفة و الهندسة المصرية فى ذلك التهان الزمان. 


\section{Novels, Cultures and Arts in Great Discoveries Khamis Gamil \\ Resumen}

En este studio exponemos el papel que los antiguos egipciosuos y finicios jugaron en la realización de nuevos descubrimientos durante su vigencia en la histoia. También hacemos una referencia al descubrmiento de nuevos horizontes que los vikingos del norte de Europe realizaron por tierras americanas continúa este estudio con una mirade al mundo después de cristobal colón. Sin duda, estos descubrimientos fueron acompañados construyeron, arte, etc.

Los fenicios construyeron ciudades importants en España como sevilla, córdoba, Valencia, Málaga o Barcelana, donde intrudujeron sus técnicas de construcción de barcos, armas, agricultura, etc.

Dice el departamento de argueología español que estas ciudades fueron erigidas sobre asentamientos fenicios. Estos fundaron igualmente numerosos puertos y fabricas de navios

Actualmente los expertos en el tema nos comentan que los egipcios llegaron hasta el Nuevo Mundo, particularmente a México, donde encontraron varias ruínas y pirámides aztecas construídas ala manera egipcia, lo que bien pudiera significar qur amibas culturas tuvieron algún tipo de contacto.

El descubrimiento del Nuevo Mundó cambió la trayectoria de la historia de la humanidad. El mito de la Atlántida tiene sus raices en las leyendas y en las tradiciones egipcias, y es ampliamente narrado en los diálogos de Platón.

La cultura romana y la medieval lo ignoran o, por lo menos, lo descuidan. Cuando Séneca, y despues Isidoro de Sevilla, aluden a tierras más allá del océano, no se refieren a la Atlántida egipcioplatónica, sino a intuiciones que aquí y allá aparecen en la cultura ibérica, no olvidemos que Séneca nació en España, como por lo demás 
en las tradiciones y en las leyendas de todos los pueblos cuyas tierras se asoman al Atlántico: celtas, irlandeses, escandinavos, aparte de otros pueblos más allá en el Oriente, como los egipcios y fenicios.

Después del descubrimiento de Colón, Caboto y Vespuccio, el mito de la Atlántida tarda en desaparecer. Se ha sostenido que Thomas More no habría escrito su Utopia si no hubiese tenido lugar el gran descubrimiento. Thomas More hace referencia a un viaje de Vespuccio para explicar cómo su protagonista llega a Utopia. Tenemos que limitar la influencia del gran descubrimiento sobre la maestra obra de More exclusivamente a los aspectos geográficos, por otra parte limitados. Sin embargo, More leyó el Mundus Novus de Vespuccio. Se trata de un texto manipulado por el editor, y publicado por primera vez en 1504. La lectura del Mundus Novus ofrece un cuadro de vida salvaje y feroz bien distinto de lo idílico de la carta de Colón a Santagel. Observa Luigi Firpo, uno de los más profundos conocedores de la obra de More y de su tiempo: "sólo una profunda fe en la razón y en su providencial autosuficiencia en la esfera mundana pudo inspirar páginas que ocultan, bajo la excelencia del latin humanistico, un tan radical empuje revolucionario. "Ninguna conexión, pues, en el plano de la sustancia ideológica, entre la utopia y el gran descubrimiento colombino.

Al respecto de la cuestión del descubrimiento, vamos a hacer un resumen y comentarios sobre las aventuras de los vikingos. Estos llegaron a Groenlandia en la primavera de 982, y allí establecieron algunas colonias. No cabe duda alguna que Helluland, alcanzado en torno al año 1000, corresponde a Terranova o a Labrador. Luego los vikingos avanzaron también más al sur, y llegaron a una tierra llena de bosques, con una playa y abigarrada por dunas de arena blanca. La llamaron Markland, o sea, , tierra de bosque '.Se trataba casi seguro de Nueva Escocia, en el Canada sudoriental. Además de Markland, las sagas islandesas hablan de Viland. Nosotros creemos que, en efecto, Leif Ericsson desembarco en Viland, Massachusetts. Pero la cristiandad no tuvo ni conservó ninguna noticia de ésto. Vinland quedó, para las generaciones posteriores al milenio, como un sueño, como una esperanza indiferenciada e imprecisa, no como una realidad

624 Annals of the Faculty of Arts, Ain Shams University -Volume 38 (October - December 2010)[ 


\section{Khamis Gamil Al-Zubaidi}

definida. Realidad fue Groenlandia, no las tierras del continente americano - Helluland, Markland, o Vinland - ocasionalmente conocidas y visitadas, no colonizadas de una forma estable, y que quedaron en algunos rincones de la cultura geográfica europea como bordes occidentales de Europa, carentes de atractivos particulares.

El pueblo vikingo contribuyó a la formación de tres de las más importantes civilizaciones del mundo: la inglesa, la latina y la rusa; dió vida a cuatro estados que están a la vanguardia del mundo moderno por su organización social, política, y económica: Noruega, Dinamarca, Suecia, e Islandia. Es posible que haya varias propuestas para explicar y aclarar más o menos la situación de los vikingos según esta pregunta: Cómo fue posible que después de haber tenido contacto con aquel El Dorado que es Norteamérica no se haya siquiera intentado colonizarlo? La primera razón es que los vikingos, durante sus visitas del siglo xvi, citadas por las sagas, vieron tierras que no se parecían en nada a El Dorado. Visitaron El Labrador, Terranova Helluland -, Y Groenlandia. Vieron y visitaron Nueva Escocia Markland -, donde, con respecto a Islandia, existían más y mejores bosques y, por lo tanto, madera, pero nada mas .Faltaban, en cambio, pastos para el ganado. Vinland fue avistado y visitado por muy pocos; fue recordado en las sagas nórdicas, pero ni siquiera fue nombrado en las crónicas; quedó casi como un sueño y no como una realidad histórica.

La segunda razón es que los vikingos de Islandia eran un pueblo inculto. Sus mismos jefes eran analfabetos. Es casi seguro que Eric el Rojo, Leif Ericsson, Thorvald y los demás protagonistas de las prodigiosas experiencias vikingas no supieran leer ni escribir. También carecían de un conocimiento geográfico profundo. $\mathrm{Ni}$ siquiera se planteaban el problema de las dimensiones y formas de la tierra, dando por descontado que era plana. Tampoco dudaron ni por un instante que los territorios avistados no fuesen islas, pero las consideraron europeas.

La tercera razón es que los hombres y mujeres que llegaron a las costas norteamericanas durante el siglo xi no eran ciertamente los mejores elementos del pueblo vikingo. Los mejores se habían dirigido y se dirigian hacia occidente, Normandía; hacia oriente, Rusia; hacia 
el sur, el Mediterráneo. Los que quedaron en Escandinavia perdieron no solamente su fiereza y virulencia, sino también el vigor y la indomable vitalidad que caracterizaron las hazañas de los siglos anteriores.

La cuarta razon es que los vikingos no encontraron en Norteamerica una civilización superior. No encontraron príncipes ni hombres ricos a quienes asesinar para robar sus bienes, ni capitales acumulados o invertidos de los cuales apoderarse por la fuerza. En Norteamérica encontraron bosques con mucha madera, que la podían encontrar más facilmente en Noruega, y pudieron hallar extensos pastos. El mayor problema es que estaban constantemente amenazados por indígenas rudos y salvajes. Contra este enemigo, los vikingos no podían contar con aquel terror que tanto favoreció sus victorias en Europa. Los skrelingos no tenían que perder, o incluso habrían podido ganar algo atacándolos y depredándolos. Los francos y los sajones, lo bizantinos y los árabes, los eslavos y los latinos, todos temían a los vikingos ; los aborígenes, sin embargo, no los temian, sino que fueron ellos, los vikingos, quienes estuvieron amedrentados ante su presencia. No valía la pena luchar contra indígenas pobres que vivían como bestias; no tenía sentido quedarse en territorios controlados por ellos.

A las leyendas amerindias se añaden las irlandesas: el viaje marítimo de San Brandano, incitado por una voz Divina a ir hacia un grande y desconocido pais de ultramar, Leyendas aztecas contaban de un desembarco en las costas mexicanas de hombres altos y rubios, con ojos azules. Un viejo de piel blanca y larga barba, sabio bondadoso y pacífico, habría desembarcado en las costas del Yucatán . Los indios le llamaron Quetzalcoatl, o sea, 'serpiente emplumada' .Le habían obedecido largamente, y luego se habian rebelado contra el y le habían obligado a marcharse ; pero antes de partir, el ya había profetizado que un día sus hermanos blancos volverían.

Las hipotesis son todavía más numerosas que las leyendas.? Llegaron a America colonos irlandeses ? Llegaron allí los genoveses hermanos Vivaldi en su aventura sin retorno, más allá de las columnas de Hercules ? Llegaron allí navegantes griegos o fenicios? O Llegaron

626 Annals of the Faculty of Arts, Ain Shams University -Volume 38 (October - December 2010)[ 


\section{Khamis Gamil Al-Zubaidi}

allí algunos marineros egipcios? Según estas cuestiones, y a la luz de estas consideraciones, resulta obvio confirmar que el problema del descubrimiento del continente americano no es de carácter deportiva, sino histórico. No se trata de establecer quién ha sido el hombre que abrió el nuevo continente al conocimiento de los continentes antiguos, que lo ensartó repentinamente, violentamente, en el desarrollo de la civilización, determinando un cambio decisivo en la historia de la humanidad. Colón fué el protagonista del gran acontecimiento porque fue inventor genuino de una nueva idea, de una nueva perspectiva. Unía a la fantasía, ala inteligencia y a la audacia una voluntad, una constancia, una generosidad de ánimo fuera de lo normal. Fué uno de los colosos de la historia. Sólo un genio podía hacer lo que hizo el genovés: concibío la idea y la concretó. Fué el primero en dar al mundo antiguo dos grandes noticias reveladoras: una estaba prevista por algún científico y era esperada por algunos marineros, pero nadie habia tenido la valentia de confirmarla; más allá del oceano no había abismo, exlstian otras tierras. En ellas desmbarcó Colón el 12 de octubre de 1492, y fue la fecha del inicio de una nueva era. La otra noticia, fabulosa y hasta entonces solo fantástica, la comprobó Colón cuando llegó a la desembocadura de un inmenso rio, el Orinoco.

Otro mundo nuevo: sólo con la empresa de Colón, Europa se dió cuenta que existía un mundo nuevo, y los hombres de América se dieron cuenta de que existía un mundo mas viejo que el suyo.

Sin embargo, el genovés fue el primero, el gran protagonista. No fué el primer hombre en hallar la tierra americana, pues muchos otros antes ya la habitaban. No fué tampoco el primer europeo en desembarcar, sea porque puede haber alguna verdad revuelta en la leyenda o en las hipotesis que surgen periódicamente, sea porque es históricamente cierto que los vikingos tocaron en el siglo xii las costas norteamericanas,

El gran hecho, escribe magistralmente Uslar Pietre, no puede ser la llegada de los europeos a un territorio desconocido, ni menos aún el comienzo de una larga etapa de colonización, que de todo ésto hubo, sino sobre todo y fundamentalmente el nacimiento de un mundo nuevo, distinto de sus progenitores, con una presencia original y un papel propio en la historia de la humanidad. 
Los Cuentos, cultura y arte de los grandes.

¿ Seria mejor hablar de 'encuentro' ? Estamos de acuerdo con Zabala y Uslar Pietri: no fue ni siquiera un mero encuentro prolongado, como fue el caso en las colonizaciones europeas en Africa y en Asia, en las que la cultura Invasora y la nativa, a pesar de la convivencia forzada, mantuvieron sus vigencias propias. Este descubrimiento representa una creacion de un mundo nuevo, que fue profundamente diferente de los dos que le dieron origen.

Verdaderamente, el tema del descubrimiento de un continente poblado y desconocido por los demás tuvo dos etapas: la primera fue la anterior a los viajes de Colón, y ls segunda la de despues. La primera empezó hace casi 3150 años. El profesor Jirazbwi - profesor de Historia en Inglaterra - hizo un comentario sobre la invasión egipcia en México. Este aseguró en su obra que los antiguos egipcios fundaron la primera civilización en Arnerica del sur , una civilización que bien pudiera haber sido la madre de todas las civilizaciones y el desarrollo de América y de México y sus civilizaciones en particular, como la Azteca, la Maya, la Inca, etc. Para mostrar su propia hipótesis, hizo una exposicion sobre los documentos escritos poe el tercer Ramses, en los cuales este anunciaba que prepararia una marina gigante para dirigirse a conquistar la tierra situada al máximo extremo del Inundo. El mismo profesor aseguro que pudo coleccionar más de sesenta ejemplares de las ruinas mexicanas antiguas. Sigue diciendo que nadie puede interpretar o entenderlas excepto a través de una comparación con escrituras antiguas egipcias. Además reconoce que entre las ruinas hay unas excavaciones muy destacadas en las cuales había unas estatuas que representan la diosa egipcia Sit, y otra que representa las barcas patrulleras egipcias del sol.

El cientifico noruego Thor Hayardal creía sin duda en la teoría de Jirazbwi. Thor intentaba mostrar la verdad de esa hipotesis y aprobar la teoria de la llegada de los egipcios a América, Este tuvo una experiencia única al montarse en un barco del mismo modelo que usaron los egipcios: un barco hecho, en parte, de papiro. El éxito de ese viaje al cruzar el océano y llegar con éxito a la costa americana muestra que los egipcios verdaderamente tuvieron la suerte de cruzar el Atlantico hace miles de años, y para ello seguramente aprovecharan

628 Annals of the Faculty of Arts, Ain Shams University -Volume 38 (October - December 2010)[ 


\section{Khamis Gamil Al-Zubaidi}

la dirección del viento entre Africa y América del sur.

Isaac Asimov, en su obra La Tierra de Canaan, citó que los egipcios y fenicios se intercambiaron madera de encinas y papiro. A para fabricar grandes barcos, junto con madera dePalestina y Jordania.

Los fenicios de la costa oriental mediterránea fueron los primeros colonizadores que, en sus navegaciones, fundaron una ciudad en la península ibérica a la que llamaron Gádir, actual Cádiz, en el año 1104 a. de c. Otras fundaciones fueron Malak, o Malaga, Abdera, Adra, y Sexi, actual Almuñecar. Desde ellas, los fenícios ejercieron su influencia sobre las poblaciones indigenas de la costa interior de Andalucía, mezclándose en ocasiones en establecimientos mixtos, organizados como ciudades - estado; estas colonias tenían una economía fundamentalmente industrial, en la cual la navegacion y el comercio ocupaban a la población. Numerosos restos de sus fábricas han aparecido a lo largo de la costa meridional de la península ibérica .También fuy muy importante su industria textil y, sobre todo, el tinte de tejidos como el rojo purpura que extraían de conchas marinas .

Cuando los asirios conquistan la ciudad de Tiro a comienzos del siglo vii a. de c. , las factorías de occidente pasaban a depender de Cartago , colonia fundada por tiro, en la actual Tunez .Bajo Cartago , la colonización fenicia alcanzó un nuevo impulso .Los cartagineses fundan Ebussos , actual Ibiza, en 654 a. de c ., así como otros puntos en las costas meridionales de la peninsula . Tanto los fenicios como los cartagineses influyeron poderosamente en la religión, el arte y cultura de la poblacion indigena $\mathrm{y}$, en especial, en el uso de la escritura.

Isaac Asimov comenta en su op. cit. que la intención fenicia a adentrarse en el mar era grande. 


\section{BIBLIOGRAFIA}

1. Platón, Gritias en el texto original en "Platones Opera" de 1. Burnett, tornos IV y IX, Oxford, pp. 113-121.

2. Campanella, "Epílogo Magno", ed. A Cura di Carmelo Ottaviano, Roma,1939.

3. Campanella, "Monarchía Hispánica Discurso", Amsterdam, 1640, R. Hakuyt, "Principal Navigation ; Voyages and Discoveries of the English Nation", Glasgow, 1903-1905, vol.viii.

4. Bacone, "Novum Orgnum", Bari, 1960 ; "New Atlantis" en Scritti Politici Giuridici e Storici", Torino, 1971.

5. De Zarate, "Historia del Descubrimiento y Conquista de la Provincia del Perú, y de las Guerras" en Historiadores Primitivos de Indias, torno 11, Madrid, 1947.

6. C.E. Brasseur de Bouborg, "Manuscrit Troano" , París, 1989.

7. P. Ternier, "L'Atlantide", Monaco, 1913.

8. R. Devigne," Un Continent Disparu: 1 'Atlantide", sixieme partie du monde, Paris, 1924.

9. G. Perrone, "L'Atlantide, Leggende e Testimonianze", Torino, 1928.

10. Berlitz, "The Mystery of Atlantis", Grsst, Bunlap, inc., New York, 1969.

11. .G. Glizzi, "Adamo e il Nuovo Mondo", Firenze, 1977

630 Annals of the Faculty of Arts, Ain Shams University -Volume 38 (October - December 2010)[ 


\section{Khamis Gamil Al-Zubaidi}

12. Luigi Eirpo, Vicenza, 1978, p.27; también véase T. Carnpanella, "La Citta del Sole", texto critico de G. Paladino, Napoli, 1920.

13. Thor Heyer , Dahl. "Aku Aku, The Secret of Easter Island", London, 1958; "The KOntiki Expedition", London, 1965., A. Metreaux, "L'llle de Paques", París, 1941.

14. P. E. Taviani, "Cristobal Colón: Génesis del Gran Descubrimiento", Novara, 1984, vol.i, pp. 256-259.

15. P.T. Taviani,"La Grande Scoperta", Novara, 1985, vol.II, pp.323325.

16. .16E. Cerull, "Razze, Lingue, Culture Indigeni de America", Torino., vol.IV, 1967; T. Todorov,"La Conquiste de L'Amerique.La question del'Autre", París, 1982, parte I, capitulo 2.

17. Roldan, Jose Manuel, "Historia de España", Madrid, 1986,p.11.

18. Asimov, Issac, "La Tierra De Canaan", alianza editorial, Madrid, 1981. Traducuda por Nestor A. Miguez, p.22-25, y 95. 